\title{
Correspondence
}

\section{Pharmacotherapy for anxiety}

Sir: Nutt \& Bell (1997) have included a section about the drug treatment of post-traumatic stress disorder (PTSD). They state that "there have been no properly controlled trials" for the pharmacological treatment of PTSD. This statement is incorrect since there have been at least eight randomised, doubleblind, controlled trials of the drug treatment of PTSD using: phenelzine (Frank et al, 1988; Shestatzky et al, 1988; Kosten et al, 1991), amitriptyline (Davidson et al, 1990), desipramine (Reist et al, 1989), imipramine (Franket al, 1988; Kosten et al, 1991), fluoxetine (Van Der Kolk et al, 1994), alprazolam (Braun et al, 1990) and brofaromine (Baker et al, 1995; Katzet al, 1994/1995).

Nutt \& Bell also recommend the addition of a benzodiazepine for more enduring cases. I would caution against this, since there is evidence that benzodiazepines are ineffective in PTSD (Braun et $a l, 1990)$ and may lead to a severe exacerbation of PTSD symptoms following withdrawal from longterm use (Risse et al, 1990).

Our own experience and that of the National PTSD Centre in the USA (Friedman, 1996) is that the addition of an $\alpha_{2}$ adrenergic agonist such as clonidine to a selective serotonin reuptake inhibitor is particularly beneficial in some of the more severe, resistant cases of PTSD, and this is consistent with evidence demonstrating abnormalities of noradrenergic neuronal regulation specific to PTSD patients (Southwicket al, 1993).

Baker, D. G., Diamond, B. I., Gillette, G., et al (1995) A doubleblind, randomised, placebo controlled multi-centre study of brofaromine in the treatment of post traumatic stress disorder. Psychopharmacology, 122, 386-389.

Braun, P., Greenberg, D., Dasberg, H., et al (1990) Core symptoms of post traumatic stress disorder unimproved with alprazolam treatment. Journal of Clinical Psychiatry, 51, 236-238.

Davidson, J., Kudler, H., Smith, R., et al (1990) Treatment of post traumatic stress disorder with amitriptyline and placebo. Archives of General Psychiatry, 47, 259-266.

Frank, B. J., Kosten, T. R., Giller, E. L., et al (1988) A randomised clinical trial of phenelzine and imipramine for post traumatic stress disorder. American Journal of Psychiatry, 145, 1289-1291.

Friedman, M. J. (1996) Conference Proceedings. The Psychobiology of Post Traumatic Stress Disorder. New York: New York Academy of Science.
Katz, R. J., Lott, M. H.,Arbus, P., et al (1994/1995) Pharmacotherapy of post traumatic stress disorder with a novel psychotropic. Anxiety, 1, 169-174.

Kosten, T. R., Frank, J. B., Ban, E., et al (1991) Pharmacotherapy for post traumatic stress disorder using phenelzine or imipramine. Journal of Nervous and Mental Disease, 179, 366-370.

Nutt, B. \& Bell, C. (1997) Practical pharmacotherapy for anxiety. Advances in Psychiatric Treatment, 3, 79-85.

Reist, C., Kauffmann, C. D., Haier, R. J., et al (1989) A controlled trial of desipramine in 80 men with post traumatic stress disorder. American Journal of Psychiatry, 146, 513-516.

Risse, S. C., Whitters, A., Burke, J., et al (1990) Severe withdrawal symptoms after discontinuation of alprazolam in eight patients with combat-induced stress disorder. Journal of Clinical Psychiatry, 51, 206-209.

Shestatzky, M., Greenberg, D., Lerer, B., et al (1988) A controlled trial of phenelzine in post traumatic stress disorder. Psychiatry Research, 24, 149-155.

Southwick, S. M., Krystal, J. H., Morgan, C. A., et al (1993) Abnormal noradrenergic function in post traumatic stress disonder. Archives of General Psychiatry, 50, 266-273.

Van Der Kolk, B. A., Dreyfuss, D., Michaels, M., et al (1994) Fluoxetine in post traumatic stress disorder. Journal of Clinical Psychiatry, 55, 517-522.

L. A. Neal Defence Medical Services PTSD Unit, Duchess of Kent Hospital, Catterick, North Yorkshire DL9 4DF

Authors' reply: Dr Neal emphasises that our statement "there have been no properly controlled trials for the pharmacological treatment of PTSD" is incorrect. As he mentions, there have been eight randomised, double-blind, controlled trials of drug treatment in PTSD, but these have been of different design duration and have studied people from different backgrounds. These studies have not been replicated using dose-ranging, multi-centre studies and as such, at the present time, would not meet criteria for any of the drugs being licensed for PTSD. Having said this, however, we would not like to imply that pharmacological treatment of PTSD should not be tried.

Our statement that it is our practice to use benzodiazepines in addition to antidepressant treatment for the more enduring cases. The position with benzodiazepines in PTSD is complicated. Open studies have suggested efficacy, although as Dr Neal states, the one double-blind trial there has been was not positive. The possible reasons for this include the choice of a short half-life drug 
(alprazolam) and the very long (six month) period of administration. In the clinical situation, some people are incapacitated by their symptoms that seem resistant to all other forms of pharmacological or psychological intervention, and it would seem reasonable to consider using benzodiazepines in these cases as adjunctive therapy to antidepressants.

We would support the use of clonidine, but there have also been reports of rebound hypertension on withdrawal of this drug and we would raise the point that clonidine is considerably more toxic than benzodiazepines or the new selective serotonin reuptake inhibitors in overdose.

What we would like to emphasise is that the condition has been poorly researched and, at the present time, no drugs are licensed for this conditions. This does not mean, however, that antidepressants should not be tried. These patients are often severely ill and warrant treatment.

D. J. Nutt, C. Bell Psychopharmacology Unit, School of Medical Sciences, University of Bristol, University Walk, Bristol BS8 1TD

\section{Continuing Professional Development Update}

We are now at the stage of consolidation and review in planning the Continuing Professional Development (CPD) programme for psychiatrists. There is still a considerable amount of work to be done before we can claim that our CPD programme has won acceptance from the great majority of clinical psychiatrists. As most of you who subscribe to Advances in Psychiatric Treatment will be registered for CPD, might I ask that you actively promote CPD among reluctant colleagues? Other medical colleges are developing continuing medical education (their form of

CPD) with considerable enthusiasm. All anticipate fierce public criticism of any branch of medicine that shies away from developing an agreed process of self-regulation for career-grade clinicians. The medico-legal implications are so obvious that I need not dwell on them.

Non-consultant career-grade colleagues often express surprise that CPD is meant to be taken up by all clinicians. They may be poorly informed about the nature of CPD, particularly if they do not have any kind of formal link with our College. Are all members of your clinical team fully informed and well advised? Could you please help by impressing on them the importance of getting involved with CPD? If there are practical problems, we are keen to be flexible with regard

to individual programmes. Your Deputy Regional Adviser (CPD) or Pauline Taggart at the College CPD Unit will help. Things are moving on apace, and we psychiatrists should lose no time in establishing an agreed CPD programme of self-regulation; otherwise, the process of regulation (dare I say, possibly through regular examinations) could be taken out of our hands.

Professor H. G. Morgan Director of CPD

\section{Erratum}

Eiser, C. (1997) Effects of chronic illness on children and their families. Advances in Psychiatric Treatment, 3, 204-210. On page 207, the second sentence under the sub-heading 'Family and ethnic issues' should read: "In diabetes, good blood sugar control is associated with good family functioning, that is children tend to have better diabetes control when the family functions well together, compared with children from families characterised by greater conflict." 